\title{
Testing Macro Organizational Theories in Laboratory Experiments
}

\author{
Satoshi Kanazawa \\ Department of Sociology, University of Illinois-Urbana
}

\begin{abstract}
Laboratory experiments provide the most rigorous method of testing scientific theories. However, their current use in organizational research is primarily limited to testing micro organizational theories where actors are individuals. I suggest the conditions under which one can test macro organizational theories in laboratory experiments, using human subjects in the role of organizations. I discuss two sequential stages of behavior (decision making and execution) and two different types of groups (democratic and dictatorial). I argue that the process of decision making in democratic groups is the only place where a logical justification is necessary for the use of human subjects in testing macro organizational theories. Using the Condorcet Jury Theorem, I demonstrate that, when four conditions are met, laboratory experiments with human subjects represent statistically conservative tests of macro theories. The four conditions are: (1) two alternative choices; (2) mean individual competence greater than .5; (3) individual decisions not too highly positively correlated; and (4) simple majority decision rule. I illustrate my argument with Hannan and Carroll's (1992) density dependence theory of organizational foundings and delineate one potential experimental design for testing the theory. @1999 Academic Press
\end{abstract}

Key Words: Condorcet jury theorem; density dependence theory; organizational ecology.

The density dependence theory of organizational ecology (Hannan and Freeman, 1989; Hannan and Carroll, 1992) is one of the most successful theories of organizations. This parsimonious and mathematically elegant theory explains organizational foundings and mortality in terms of a single variable: Organizational density in the population. At low density, the legitimation process dominates and leads to high organizational founding rates and low organizational

I thank Heather A. Haveman, Michael Hechter, Douglas D. Heckathorn, Christine Horne, Sarah A. Soule, Michael W. Macy, Linda D. Molm, James Ranger-Moore, Joseph M. Whitmeyer, David Willer, and Morris Zelditch, Jr. for their comments on earlier drafts of this paper, and David M. Estlund, Krishna K. Ladha, and Martin T. Wells for their technical help. Special thanks go to Heather A. Haveman for helping me to broaden the scope of this paper and address a larger audience.

Address correspondence and reprint requests to Satoshi Kanazawa, Department of Sociology, MC-454, Lincoln Hall, University of Illinois-Urbana, 702 South Wright Street, Urbana, IL 618013695. E-mail: satoshi@uiuc.edu. 
mortality rates. At high density, the competition process dominates and leads to low organizational founding rates and high organizational mortality rates. The theory has been tested using archival data (Hannan \& Freeman, 1987, 1988; Carroll \& Hannan, 1989a; Carroll \& Swaminathan, 1991), analyzed with computer simulations (Hannan, Ranger-Moore, \& Banaszak-Holl, 1990; Hannan \& Carroll, 1992, Chapter 8), and with the use of a formal logical language (Péli, Bruggeman, Masuch, \& Ó Nualláin, 1994).

One method that has not been used so far to test the density dependence theory is the laboratory experiment. Laboratory experiments provide the most rigorous testing of hypotheses derived from general and abstract theories. By allowing maximal control over extraneous variables through randomization, the experiment provides the most unambiguous evidence for causation, and thus for confirmation or disconfirmation of causal hypotheses (Aronson, Brewer, \& Carlsmith, 1985, p. 443). Methodologists generally concur that experimental data, where possible, are better than nonexperimental data for causal inference (Costner \& Leik, 1964, pp. 824-825; Costner \& Blalock, 1972, p. 836; Arminger \& Bohrnstedt, 1987, p. 370; Berk, 1988, p. 155). Some even go so far as to claim that causes are only those things that could, in principle, be treatments in experiments (Cook \& Campbell, 1979, pp. 25-28; Holland, 1986, p. 954).

Many have advocated the use of laboratory experiments in the study of organizations (Zelditch \& Hopkins, 1961; Weick, 1965; Zelditch, 1969). However, all of these statements call for the use of laboratory experiments to test micro organizational theories about the behavior of individuals within organizations. In such experiments, human subjects play the role of organizational members within the experimental analog of an organization, and their behavior is used to test micro organizational theories, which predict the behavior of individuals within organizations. Zucker's (1977) study on cultural transmission and institutionalization is an example of just such an experiment.

In this paper, however, I call for the use of laboratory experiments to test theories of macro organizational behavior. I will argue that, under reasonable conditions, human subjects may play the role of corporate actors (organizations) to test theories about the behavior of organizations, not organizational members. I will illustrate my argument by showing how the density dependence theory of organizational foundings can be tested in a laboratory experiment. There are three separate logical justifications for the use of laboratory experiments to test theories of corporate behavior.

Many have argued that an individual is not a singular entity but is composed of many parts or "multiple selves" with conflicting interests. Abell (1989) speaks of the "internal prisoner's dilemma" between the egoistic and altruistic motivations within a single individual. Schelling (1984) discusses the contest for selfcommand between " "straight' ego" (with a low discount rate) and "wayward alter" (with a high discount rate), in what Elster (1989) calls an intrapersonal collective action problem. Ainslie (1992) talks about successive motivational states within a single person, in his call for a new economics with smaller units of 
analysis than microeconomics: Picoeconomics. If one can assume (as one does when testing micro organizational theories in laboratory experiments with human subjects) that individuals can coordinate conflicting interests of these subunits within themselves and act rationally with a consistent preference hierarchy, then it is a mere logical extension to argue that corporate actors can coordinate conflicting interests of their subunits (individuals) and act rationally with a single preference hierarchy. ${ }^{1}$

Berger, Eyre, and Zelditch (1989) have a different approach. They argue that general and abstract theories are neither micro nor macro. Instead, micro and macro levels are two interpretations or applications of the same general and abstract theory. Actors in such theories can therefore be individuals (in their micro interpretation or application) or collectivities (in their macro interpretation or application). Berger, Eyre, and Zelditch (1989, pp. 16-21) use Emerson's (1962) power-dependence theory as an example of such general and abstract theory. In its micro application, the theory can explain the power-dependence relationship of a husband and a wife in a marriage; in its macro application, it can explain the multilateral relations of organizations. But it is still the same theory. From this perspective, laboratory experiments with human subjects provide one particular (micro) interpretation which tests and supports the general and abstract theory. Once supported, the same theory can be used to explain the behavior of corporate actors in a different (macro) interpretation.

I will not pursue these lines of defense in this paper, however. Following Feld and Grofman (1990), I will instead emphasize the social and purposive nature of corporate actors. I will discuss how actors "behave" and two different types of groups, and argue that the only place where logical justification is necessary to test macro organizational theories in laboratory experiments is the process of decision making in democratic groups. Because the Condorcet Jury Theorem (Condorcet, 1785) demonstrates that, under certain conditions, collective decisions are always superior to individual decisions, using human subjects in laboratory experiments to test macro theories of corporate actors will provide statistically conservative tests of such theories.

\section{TWO STAGES OF BEHAVIOR: DECISION MAKING AND EXECUTION}

One can justifiably test a macro organizational theory in a laboratory experiment, with human subjects in the roles of organizations, if and only if one can show that individuals in the experiment are reasonable substitutes for organizations in the theory with respect to the relevant experimental variables. If the human subjects react to experimental manipulations differently from how organizations react to the correspondent theoretical variables, the experimental test will neither confirm nor disconfirm the theory's hypotheses; it will just be irrelevant.

All behavior (of both individual and corporate actors) consists of two sequential stages: making a decision, and carrying out the decision. For individual

\footnotetext{
${ }^{1}$ I thank Douglas D. Heckathorn and Christine Horne for independently suggesting this idea to me.
} 
behavior, both are performed by the same entity; the individual makes a decision and then, subsequently, carries out the decision. For corporate behavior, regardless of how decisions are made for the group, they are always carried out by an individual, in typical principal-agent relations (Jensen \& Meckling, 1976; Friedman, 1986; Petersen, 1993). Groups cannot behave in the true sense of the word; only individuals can, as agents acting on behalf of groups (Lawler, Ridgeway, \& Markovsky 1993, p. 272n). So for the second stage of behavior, using human subjects in place of corporate actors in laboratory experiments entails no logical problem. In both laboratory experiments and natural settings, it is always the individual who carries out the decision, and human subjects are reasonable substitutes for the agents for corporate actors. ${ }^{2}$

The use of human subjects to model the first, decision making stage of corporate behavior still needs to be justified. With respect to the decision-making process, there are two ideal types of groups. In democratic groups, collective decisions reflect the individual decisions by all members. In dictatorial groups, "collective decisions" are made by a single individual, the dictator. The use of human subjects to model the process of decision making in dictatorial groups once again presents no logical problem because the entity that makes the decision in laboratory experiments and the one that does so in natural settings are the same. (One can justifiably test macro organizational theories in laboratory experiments with human subjects if "organizational decisions" are always purely individual, dictatorial decisions of the entrepreneur or the manager.) This means that the only place that requires logical justification is the process of decision making in democratic groups. ${ }^{3}$

\section{DECISION MAKING IN DEMOCRATIC GROUPS}

Condorcet (1976, pp. 33-70) was the first to discuss the possibility of cyclical collective decisions. Under certain conditions, the aggregation of individual preferences results in a collective choice to which a majority prefers another choice. Assume that a collectivity faces three potential choices: $a, b$, and $c$. If a third of the collectivity has the transitive preference hierarchy $a>b>c$, a third has $b>c>a$, and another third $c>a>b$, a two-thirds majority prefers $a$ to $b$,

2 This does not mean that agents always faithfully carry out the decisions and wishes of the principals. The extent to which agents do so is a variable, affected by various external conditions. The point is that the entity in theory and in natural settings (the agent) is the same as the actor in the experimental test; both are individuals. Then human subjects can be used to test causal hypotheses about agents' behavior in a laboratory experiment. Causal hypotheses about corporate actors' decision making (the main focus of this paper) and those about their decision execution (via agents) must thus be tested in separate experiments.

3 There is a third ideal type of groups: Oligarchical groups, where a small subset of the group (the oligarchs) makes the decision for the group. However, one can think of the oligarchs as a small democratic group within a larger group; the group decisions reflect the individual decisions of all oligarchs. Thus, if I can justify the use of human subjects to model the process of decision making within democratic groups of all sizes, then I can justify the use of human subjects for the same process within oligarchical groups. 
another two-thirds majority prefers $b$ to $c$ and another two-thirds majority prefers $c$ to $a$, making the collective choice intransitive, even though every single member of the collectivity holds a transitive preference hierarchy. Then, in his Nobel prizewinning work, Arrow (1963) demonstrates that there is no general method, with reasonable restrictions, of aggregating individual decisions to form a collective choice which avoids this cyclical pattern. In other words, there is no general method of always producing transitive collective preferences even when individual preferences are transitive.

Arrow's argument, however, assumes the existence of "impartial culture" (Garman \& Kamien, 1968; Gehrlein \& Fishburn, 1976), where any individual preference ordering is as likely to happen in the population of voters as any other (Arrow, 1963, p. 59; Plott, 1967; Niemi \& Weisberg, 1968). ${ }^{4}$ Impartial culture is thus a random collection of voters with respect to preference orderings. But a group in natural settings is never a random collection of individuals. As Skog (1993, p. 207) notes, natural groups represent a very limited space in the universe of all mathematically possible collections of individual preferences. In natural settings, members of a group always share certain goals and purposes in common.

Natural groups, such as organizations, are thus purposive and pursue certain collective goals. This observation has two implications. First, given a set of collective goals, certain group decisions are "right" and others are "wrong." "Right" group decisions are those that promote the group goals, and "wrong" ones are those that hinder them. ${ }^{5}$ The fact that it is often difficult and sometimes impossible to tell whether a given group decision is a right one is inconsequential. A right decision is the one that an individual would make in light of full information. Second, because the raison d'être of a natural group is to achieve group goals, all group decisions ultimately pertain to the achievement of these goals. For instance, all decisions that a capitalist firm makes ultimately pertain to the pursuit of increasing profits and market shares.

Right and wrong decisions in this sense need not reflect any objective scientific reality. Group goals may be entirely socially constructed. Residents of Salem Village, Massachusetts, in the 17th century, decide to form a group for the purpose of finding and executing witches. In the minds of these people, witches exhibit certain behavioral traits. Then the decision to execute the person who exhibits these traits most frequently is the right decision, and the decision to execute another who exhibits them less frequently is the wrong decision, whether or not

${ }^{4}$ In fact, Chapter 7 of Arrow's Social Choice and Individual Values (1963) mostly discusses how his famous conclusion, that there is no satisfactory general social welfare function, does not hold when citizens share certain common preference orderings.

5 I follow Black (1958, pp. 164-165) and use the terms "right" and "wrong" without any moral or other implications. Decisions are "right" or "wrong" only relative to group goals. Right decisions are efficacious with respect to such goals, and wrong ones are inefficacious. I choose to use right/wrong, rather than efficacious/inefficacious or other more descriptive terms, purely for their simplicity. While I will not put these terms in quotation marks below, the reader should always remember that the terms are mere shorthand. Further, the right/wrong dimension is continuous, not dichotomous; I use the dichotomous labels for the ease of presentation. 
witches exist in reality. Note that people in Salem Village, with their limited information, may make a wrong decision and decide to execute the "wrong" person, but someone with full information (a complete list of putative behavioral traits of witches and the actual behavioral traits of all persons in Salem Village at all times) can always make the right decision.

\section{THE SUPERIORITY OF COLLECTIVE DECISIONS: THE CONDORCET JURY THEOREM}

Given that natural groups like organizations are purposive, how can the process of decision-making in democratic groups be represented by human subjects? The key to the logical justification for this is a mathematical principle known as the Condorcet Jury Theorem (CJT).

The CJT demonstrates that a majority of a democratic group is always better at choosing the superior of two alternatives than any single individual (Condorcet, 1785; Black, 1958, pp. 164-165; McLean \& Hewitt, 1994, pp. 34-40). In its original formulation, the CJT assumes the following conditions (even though all of these conditions will be relaxed below):

(1) There are exactly two alternatives.

(2) All individuals share a common preference such that one of the two alternatives is superior for all in light of full information.

(3) Each individual makes the right decision with the probability $p>.5$; individuals are homogeneous in $p . p$ is known as individual competence.

(4) The individual decisions are independent of one another.

(5) The collective decision rule is simple majority.

If all these conditions hold, then the probability that a majority of a group of size $n$ makes the right decision, $\mathrm{P}_{n}$, is always greater than $p$, and very quickly approaches 1 as either $n$ or $p$ increases (see Ladha, 1992, Appendix, for proof of the CJT in its original formulation; see Miller 1986, p. 176, Table 1, for values of $\mathrm{P}_{n}$ for selected values of $p$ and $n$ ).

An important implication of the CJT is that, if a natural group finds itself in an informational environment that would allow an individual to make the right decision with a certain probability $(p)$, then the group can always make the right decision with a higher probability $\left(\mathrm{P}_{n}>p\right)$. This means that using human subjects to act as groups to test macro organizational theories about corporate behavior in laboratory experiments consistently underestimates the probability that the groups will make the right decision. Then, as long as the macro theories being tested are based on the premise that groups are purposive actors, laboratory experiments always provide statistically conservative tests of the theories.

The five conditions under which the CJT holds in its original formulation are very restrictive, and many organizations may find themselves in an environment that violates some or all of them. Fortunately, however, all five conditions can be relaxed to a significant degree, allowing experimental testing of many macro organizational theories. 
What If There Are More Than Two Alternative Choices? (Relaxing Condition 1)

The CJT even in its latest formulation (Kanazawa, 1998) still technically requires that there be only two alternative choices. However, any multiple-choice situation can be reduced to a two-choice situation by considering two at a time. If there are three potential choices (A, B, C), then the members of an organization can first vote on the choice between $\mathrm{A}$ and $\mathrm{B}$, then on the choice between the winner of the first vote and C. As I note above, the Condorcetian cycle will not occur when the organization is purposive and its members share common interests.

\section{What If There Are No Right and Wrong Decisions? (Relaxing Condition 2)}

In a significant extension of the CJT, Miller (1986) demonstrates that it is not necessary for there to be "right" and "wrong" decisions for the CJT to work (see Miller, 1986, pp. 177-183, for proof). In other words, the theorem can be extended from "juries" in the original formulation (where there are right and wrong decisions on which all jurors would agree in light of full information) to "electorates" (where no such agreement may exist even in light of full information) (Miller, 1986, p. 178). Miller (1986) shows that the probability that the majority opinion prevails, $\mathrm{P}_{n}^{\prime}$, is greater than the individual competence, $p$ (now redefined as the probability that individuals vote, under limited information, for their "true" interest for which they would vote in light of full information $)^{6}$ as long as $n$ is large. If one argues that the majority opinion is the "right" decision for democracies, then a large group (electorate) is still better at making the right decision than individuals. Thus Condition 2 above (that there be right and wrong decisions) is not necessary for large groups.

\section{What If Individuals Are Not Homogeneous in Their p? (Relaxing Condition 3)}

Boland's (1989) and Kanazawa's (1998) extension of the CJT demonstrates that individuals need not be homogeneous in their competence in order for the CJT to work. In fact, for any given mean individual competence, heterogeneous groups are better at making the right decision than homogeneous groups. (See Kanazawa, 1998, for proof). The only catch is that the mean individual competence must be at least $\frac{1}{2}+1 / 2 n$, rather than $\frac{1}{2}$ as in the original formulation. $\frac{1}{2}+$ $1 / 2 n$ has a limit at $\frac{1}{2}$ as $n$ increases, so this is not a stringent condition for large groups. But for a group of three, for example, the mean individual competence must be at least .67 , and it must be at least .55 for a group of 10 . Note, however, that this is only a constraint on the mean; there can be individual members with significantly lower $p$ 's as long as there are others with significantly higher competence to bring up the mean.

${ }^{6}$ Note that individuals may not always be able to vote for their true interest under limited information. 


\section{What If Individual Decisions Are Not Independent? (Relaxing Condition 4)}

Ladha (1992) relaxes the condition in the original CJT that individual decisions be independent of one another and extends it to cases where they are correlated. He demonstrates that the CJT holds even when individual decisions are correlated, as long as

$$
\overline{\mathrm{r}}<\bar{p}-\frac{n}{n-1} \frac{(\bar{p}-0.25) \overline{\mathrm{q}}}{\bar{p}} \equiv \mathrm{r}^{*}(n, \bar{p}),
$$

where $\mathrm{r}_{\mathrm{ij}}=$ the probability that individuals $\mathrm{i}$ and $\mathrm{j}$ simultaneously make the right decision $\left(=p_{\mathrm{i}} p_{\mathrm{j}}\right.$ if the decisions are independent $)$;

$$
\overline{\mathrm{r}}=\frac{\sum_{\mathrm{i}}^{n} \sum_{\mathrm{j} \neq \mathrm{i}}^{n} \mathrm{r}_{\mathrm{ij}}}{n(n-1)}, \quad \bar{p}=\frac{\sum_{\mathrm{i}}^{\mathrm{n}} p_{\mathrm{i}}}{n}, \text { and } \overline{\mathrm{q}}=1-\bar{p}
$$

(see Ladha, 1992, Appendix, for proof). Thus, the CJT holds, and a group is better than the mean individual at making the right decision, even when individual decisions are correlated as long as their correlation is not too high. In particular, it is important to note that Ladha's (1992) sufficient condition above only sets the upper limit (in terms of positive correlations), and not the lower limit, to such correlations. In fact, negative correlations among individual decisions facilitate the superiority of collective decisions; groups where individual decisions are negatively correlated perform better than those where individual decisions are independent (Ladha, 1995, Corollary 2), just as heterogeneous groups perform better than homogeneous ones (Kanazawa, 1998, Theorem 1).

Estlund (1994) argues that interpersonal influence (where some individuals defer to others' opinions) does not necessarily eliminate independence of individual decisions. In particular, he demonstrates that, when the opinion leader to which individuals defer is outside of the group, independence of individual decisions holds as long as $p_{\mathrm{i}}>\mathrm{f}_{\mathrm{i}}$, where $\mathrm{f}_{\mathrm{i}}=\mathrm{i}$ 's fidelity to the opinion leader (a proportion of decisions where i concurs with the opinion leader). For instance, if i's competence $p_{\mathrm{i}}=.7$, then independence holds as long as i defers to the external opinion leader less than $70 \%$ of the time. Independence is violated only when deference is "blind and partial," in that individuals defer to the opinion leader some of the time but randomly choose which times (Estlund, 1994, pp. 152-156). Independence holds if partial deference is "wise," in that $p_{\mathrm{i}}>\mathrm{f}_{\mathrm{i}}$.

What if the opinion leader is internal to the group? Estlund (1994, pp. 158-159; personal communication) first points out that if the correlation between the decisions of two individuals is 1.0 (by always choosing the same alternative), then it is equivalent to treating these two individuals as one, and thereby reducing $n$ by 1 (Grofman and Feld, 1988). Since $\mathrm{P}_{n}$ increases with $n$, a perfect correlation thus decreases the group competence. Estlund further maintains that, if the correlation is less than 1.0, the damage to the group competence is less than if the correlation 
is 1.0. If individuals defer to an opinion leader to an unknown degree (but always $\mathrm{f}_{\mathrm{i}} \leq 1.0$ ), then the group competence, lowered by such interdependence of decisions, will be at least $\mathrm{P}_{n-1}$ among the members who are not the opinion leader. In general, a conservative estimate of the group competence with interdependent decisions created by deference to internal opinion leaders is $\mathrm{P}_{(n-\mathrm{m})}$, where $\mathrm{m}=$ the number of opinion leaders. In essence, the interdependence of decisions due to deference to opinion leaders results in group competence as if opinion leaders do not exist, and making a collective decision among the remaining members.

Because interdependent decisions are probably prevalent within organizations, I will explore this condition for the CJT a bit further and discuss its implications for experimental testing of macro organizational theories. I will illustrate Ladha's (1992, 1995) and Estlund's (1994) conclusions with a hypothetical seven-person organization and discuss two potential causes of interdependent individual decisions: Coalitions (which creates negative correlations) and interpersonal influence (which creates positive correlations).

Coalitions. Assume that a hypothetical organization consists of seven individuals and that $p_{1}=.3, p_{2}=.4, p_{3}=.5, p_{4}=.6, p_{5}=.7, p_{6}=.8, p_{7}=.9$. In other words, Individual 7 is the most competent member of this organization, and Individual 1 is the least competent. In this illustration, $\bar{p}=.6, n=7$, and $r^{*}(7, .6)=.33$. Negative correlations of individual decisions result when there are opposing coalitions or schools of thought, if members of different coalitions vote for different choices. Assume that there is a "majority" coalition of four individuals, and a "minority" coalition of three individuals, within the hypothetical seven-person organization. Either coalition can move first, before the other. When a coalition moves first, I assume that its members vote on the alternative choices within the coalition (breaking ties with a coin toss) and reach a collective decision for the coalition. Then all members of this coalition vote for this choice when members of the organization meet to make a collective choice for the organization, and the members of the other coalition will necessarily vote for the other choice.

I consider three possible majority coalitions: "Competent" coalition (Individuals 4, 5, 6, and 7); "median" coalition (Individuals 1, 3, 5, and 7); and "incompetent" coalition (Individuals 1, 2, 3, and 4). For each majority coalition, I consider the possibility of the majority's moving first or the minority's moving first. Table 1 presents $\bar{r}$ for each of the six possible scenarios. Regardless of who comprises the majority coalition or which coalition moves first, $\bar{r}$ is always smaller than the critical value of $\mathrm{r}^{*}=.33$. Thus, the CJT holds and the collectivity is more competent than the mean individual when there are two opposing coalitions. It appears that the existence of coalitions that disagree on which alternative choice is right guarantees the superiority of the collective judgment, at least when the coalitions are relatively equal in size. This result is consistent with Ladha (1995, Corollary 2). 
TABLE 1

Coalitions

\begin{tabular}{lcc}
\hline & \multicolumn{2}{c}{$\overline{\mathrm{r}}$} \\
\cline { 2 - 3 } \multicolumn{1}{c}{ Majority } & $\begin{array}{c}\text { Majority } \\
\text { moves first }\end{array}$ & $\begin{array}{c}\text { Minority } \\
\text { moves first }\end{array}$ \\
\hline Competent $(4,5,6,7)$ & .23 & .18 \\
Median $(1,3,5,7)$ & .18 & .16 \\
Incompetent $(1,2,3,4)$ & .14 & .17 \\
\hline
\end{tabular}

Note. $\mathrm{r} *(7, .6)=.33$.

Interpersonal influence. Since the CJT is more difficult to hold in the face of internal opinion leaders than external ones, and since internal opinion leaders are probably more common, I will illustrate the implications of Estlund's (1994) argument for interdependent decisions created by deference to other members of the organization. His argument suggests that CJT will still hold and $\mathrm{P}_{(n-\mathrm{m})}>\bar{p}=$ .6 if: (1) the ratio $\mathrm{m} / \mathrm{n}$ is not high, so that there are still many effective voters left in the organization after the opinion leaders are removed for the purpose of computing the group competence; and (2) $\bar{p}$ among the remaining $(n-\mathrm{m})$ members remains high.

Table 2 presents what happens when there are one, two, or three opinion leaders in the hypothetical seven-person organization and when the condition $\mathrm{P}_{(n-\mathrm{m})}>\bar{p}$ fails to hold. When there is only one opinion leader, then the group competence among the remaining six members is still higher than the mean individual (before the removal of the opinion leader; $\bar{p}=.6$ ) in all cases except when Individual 7 is the opinion leader. When the most competent individual is the opinion leader and other members of the organization defer to Individual 7 to unknown degrees, then $\mathrm{P}_{(n-\mathrm{m})}<.6$ and the group competence will be less than the competence of the mean individual. Note, however, that the use of human subjects in the role of this organization would still be justified in most (86\%) of the cases.

Similarly, there are four combinations of two opinion leaders, involving either or both of the two most competent members, which would make $\mathrm{P}_{(n-\mathrm{m})}<\bar{p}$.

TABLE 2

Interpersonal Influence

\begin{tabular}{clc}
\hline $\begin{array}{c}\text { Number of } \\
\text { opinion leaders }\end{array}$ & $\begin{array}{c}\mathrm{P}_{(\mathrm{n}-\mathrm{m})}>\bar{p} \text { unless } \\
\text { the opinion leaders are }\end{array}$ & \% CJT holds \\
\hline 1 & $\{7\}$ & $86 \%$ \\
2 & $\{4,7\}\{5,6\}\{5,7\}\{6,7\}$ & $81 \%$ \\
3 & $\{1,6,7\}\{2,5,7\}\{2,6,7\}$ & $69 \%$ \\
& $\{3,4,7\}\{3,5,6\}\{3,5,7\}$ & \\
& $\{3,6,7\}\{4,5,6\}\{4,5,7\}$ & \\
& $\{4,6,7\}\{5,6,7\}$ & \\
\hline
\end{tabular}


However, the use of human subjects for the organization is justified in $81 \%$ of the cases where there is interdependence of decisions due to deference to two internal opinion leaders. There are 11 combinations of three opinion leaders, once again, always involving one or both of the two most competent members, which would render the group competence below .6. The use of human subjects in the role of this organization is still justified in $69 \%$ of the cases. While the failure rates for the CJT in this example appear high, particularly in comparison to the conventional level of Type 1 error $(p<.05)$, note that my conclusions above are based on very conservative estimates of group competence. Following Estlund (1994), I have used the lowest estimate of group competence under interpersonal influence, by assuming that the opinion leader ceases to exist for the purpose of collective decision-making.

Estlund's (1994) argument therefore leads to a highly counterintuitive conclusion: Interpersonal influence within an organization is detrimental to group competence only when the opinion leaders are competent. ${ }^{7}$

\section{What If a Group Uses a Different Collective Decision Rule? (Relaxing Condition 5)}

Kanazawa (1998) demonstrates that the CJT extends from simple majority rule to any supermajority rule, as long as the mean individual competence is at least

$$
\frac{\pi(n+1)}{n},
$$

where $\pi=$ the proportion required for collective decision $\left(\pi=\frac{1}{2}\right.$ for simple majority) (see Kanazawa, 1998, for proof). Thus, supermajority rules $\left(\pi>\frac{1}{2}\right)$ require higher mean individual competence. For instance, for a heterogeneous group of 100 (e.g., U.S. Senate), the mean individual competence can be as low as .505 for the group to be superior to the mean individual if the collective decision is simple majority. However, it must be at least .606 if the collective decision rule requires a three-fifths majority, and at least .673 for a two-thirds majority. Supermajority rules, therefore, make it more difficult for corporate actors to be right.

\section{SUFFICIENT CONDITIONS FOR EXPERIMENTAL TESTING OF MACRO ORGANIZATIONAL THEORIES}

To sum up, the Condorcet Jury Theorem and its subsequent extensions suggest that, under the following conditions, a collectivity is superior to an individual in making the right decision. Then, when a theory's conception of the organization

7 I reach the same conclusion with a completely different operationalization of interpersonal influence, where I assume that interpersonal influence results in genuine changes in individual competence. In this scenario, regardless of the strength of such interpersonal influence, the resultant interdependent decisions increase the group competence (in that $\overline{\mathrm{r}}<\mathrm{r}^{*}$ ) only when the opinion leader is incompetent. These results are available upon request. 
satisfies these conditions, laboratory experiments provide simultaneously maximally rigorous and statistically conservative tests.

\section{There Are Two Alternative Choices}

Given the purposive nature of organizations, a larger number of choices can be handled by considering two at a time, and the Condorcetian cycles will not occur. When the group is small, all members have to share common goals such that, in light of full information, all members would agree on which is the superior choice. Such agreement is not necessary when the group is large, however.

\section{The Mean Individual Capability to Make the Right Decision Is at Least .50}

While heterogeneous groups perform better than homogeneous ones, their mean individual competence must be slightly higher $\left(\frac{1}{2}+1 / 2 n\right)$.

\section{Individual Decisions Are Not Too Highly Positively Correlated}

The mean probability that any two individuals simultaneously vote for the right decision $(\overline{\mathrm{r}})$ must be smaller than

$$
\bar{p}-\frac{n}{n-1} \frac{(\bar{p}-0.25) \overline{\mathrm{q}}}{\bar{p}} .
$$

Negative correlations are conducive to superior collective decisions. Deference to external opinion leaders does not violate independence of decisions as long as $p_{\mathrm{i}}>\mathrm{f}_{\mathrm{i}}$. Deference to internal opinion leaders preserves the CJT as long as the opinion leaders are not very competent.

\section{Collective Decision Rule Is Simple Majority}

If the group uses some other majority rule, the mean individual competence must be higher.

\section{AN ILLUSTRATION: AN EXPERIMENTAL TEST OF THE DENSITY DEPENDENCE THEORY OF ORGANIZATIONAL FOUNDINGS}

I will illustrate my argument with Hannan and Carroll's (hereafter HC) (1992) density dependence theory of organizational populations. It is a highly abstract and general theory, which is precisely the kind of theory suitable for experimental testing (Martin and Sell, 1979), that is, if the sufficient conditions enumerated above are satisfied.

My claim in this illustration is not that one can always use human subjects in the roles of organizations (or their founders). Organizations have many facets and behave in different ways in different contexts, some consistent with the above conditions, others not. A macro organizational theory only purports to explain an 
organization's behavior in limited contexts; theories always have scope conditions (Walker and Cohen, 1985; Cohen, 1989). Justification for experimental testing must, therefore, be specific to theories or hypotheses. There may be other theories of organizations, or even specific hypotheses within a theory, which are not suitable for experimental testing.

The theoretical and empirical unit of analysis for the density dependence theory is the population. For the founding process, for example, HC (and their collaborators) observe a community (such as Argentina or Manhattan), which is a collection of potential organizational founders and count the number of organizations actually formed within a certain time period in the entire community. They must observe the entire community in order to avoid selection bias. In their theory, the nonevent (unrealized potential founding) is just as important as the event (actual founding) (Carroll and Hannan, 1989b, p. 546).

Zucker (1989) criticizes the density dependence theory for its total neglect of individual actors. She asks, "Where is the actor? Who founds an organization, and why?" (p. 544). In essence, Zucker criticizes the macro organizational density dependence theory for the absence of its microfoundations. Lomi (1995) argues that the exclusive focus on the population level may not be appropriate for the study of organizational foundings due to unobserved heterogeneity within the population. Because the organizational population is internally differentiated by region, and different regions within the population respond heterogeneously to the general processes of legitimation and competition, an examination of the microfoundation of organizational ecology may be necessary.

In their response, HC (1992, pp. 197-200; Carroll and Hannan, 1989b) maintain that "it is a strategic mistake to attempt to specify empirical founding processes at the level of the potential founder because it is so unlikely that relevant information on all potential founders can be found" (HC, 1992, p. 198; emphasis added). This is because, in a community of $n$ individuals, "potential founders" include not only all $n$ individuals but also

$$
\begin{gathered}
\frac{n *(n-1)}{2} \text { dyads, } \\
\frac{n^{*}(n-1) *(n-2)}{3 !} \text { triads, }
\end{gathered}
$$

and so forth. "The size of the risk set quickly becomes impractically large" (Carroll and Hannan, 1989b, p. 546). Partly for this reason, HC (1992, pp. 195-197; Hannan, 1992) call for the construction of "robust" macro theories without regard to the micro processes producing the macro phenomena. "Efforts to build microfoundations and assess their relevance are sure to be hampered by a general lack of data" (HC, 1992, p. 200; emphasis added).

I agree with $\mathrm{HC}$ that it is virtually impossible to collect data on all potential founders, especially since there is no limit to their size; it could be one individual, 
two individuals, or 20 individuals. That is, it is impossible to collect such data in natural settings; it is relatively easy to do so in a laboratory experiment. Experimental testing of the density dependence theory will be justified if the corporate actor "potential founder"8 satisfies the four conditions enumerated above. If so, then human subjects can represent potential founders of any size; the size of founders is not important in the theory. Note that HC's decision to ignore the microprocesses and concentrate on the macro theory is a purely strategic one, necessitated by the general lack of data (see the quotes above). They seem to have no theoretical or philosophical objection to building a multilevel ("micromacro") theory in the "Coleman boat" fashion, if possible (Hannan, 1991, pp. 117-119). A laboratory experiment will allow them to overcome the problem of selection bias (left censoring) which necessitated HC's decision to study the entire community, not just organizations actually founded, because the experimenter will be able to observe the behavior of all subjects, those who found an organization and those who don't, in the laboratory. A laboratory experiment will also provide an especially ideal method of testing the density dependence theory because HC intend the theory to be both general (Carroll and Hannan, 1989b, p. 546) and abstract (apparent from the fact that their key variables-legitimation and competition-remain latent and unmeasured).

When a group of individuals decides to found a new organization, they have a specific purpose in mind, whether to produce and sell certain products or provide certain services in the market for profit (in the case of capitalist firms) or to pursue some religious, moral or other interests (in the case of voluntary organizations). Thus, when faced with two alternative choices (for a potential site for their office or headquarters or for specific organizational policy), all members of an organization would agree on which of the two is the superior alternative in light of full information, even though they may disagree on actual choice given limited information.

March and Olsen (1976) contend that organizations often make their collective choices under ambiguity. They distinguish four separate types of ambiguity.

${ }^{8}$ In this illustration, I will concentrate on the founding process only (and leave out the mortality process), for three reasons. First, this is where Zucker's (1989) original criticism of HC's neglect of individuals began, and the latter defend their decision to concentrate on the macro level on the impossibility of collecting data on all potential founders. Second, the founding process is theoretically more elegant than the mortality process because there are various ways organizations can die (disbanding, absorption, merger, suspension) while the organizational founding is a unitary event (HC, 1992, p. 116). Third, mostly for this reason, the theory can predict foundings better than mortality (Carroll and Hannan, 1989a; HC, 1992).

${ }^{9}$ Dutch rational choice sociologists invented the term "Coleman boat" to refer to the macro-tomicro-to-macro causal model that James S. Coleman expounds in Chapter 1 of Foundations of Social Theory. However, the origin of Coleman boat goes back to McClelland (1961), who even uses the specific example of the effect of Protestant ethic on the development of modern capitalism (compare the figures on McClelland (1961, p. 47) and Coleman (1990, p. 8)), even though, to the best of my knowledge, Coleman has never acknowledged McClelland for this. I thank Siegwart Lindenberg and Michael W. Macy for this information. 
The first is the ambiguity of intention. Many organizations are characterized by inconsistent and ill-defined objectives. It is often impossible to specify a meaningful preference function for an organization that satisfies both the consistency requirements of theories of choice and the empirical requirements of describing organizational motive. The second lack of clarity is the ambiguity of understanding. For many organizations the causal world in which they live is obscure. Technologies are unclear; environments are difficult to interpret. It is hard to see the connections between organizational actions and their consequences. The third lack of clarity is the ambiguity of history. The past is important, but it is not easily specified or interpreted. History can be reconstructed or twisted. What happened, why it happened, and whether it had to happen are all problematic. The fourth lack of clarity is the ambiguity of organization. At any point in time, individuals vary in the attention they provide to different decisions; they vary from one time to another. As a result the pattern of participation is uncertain and changing. (p. 12)

Only the first type of ambiguity is detrimental to the experimental testing of macro organizational theories. If organizational goals are so truly inconsistent and ill-defined that organizational members with perfect and complete information could not agree on which of the two alternative choices would be better for the organization at any given time, then one cannot use the CJT to aggregate their individual decisions to derive a superior collective decision. Even in this case, however, one can use Miller's (1986) refinement of the CJT to point out that, if the organization is large enough, the collective decision still accurately reflects the true preferences of the majority of organizational members. Further, inconsistency of organizational goals over time is not a problem for the CJT.

The other three types of ambiguity that March and Olsen discuss do not hinder the experimental testing of macro organizational theories. Omniscient organizational members (with perfect and complete information) would not face ambiguities of understanding, history, and organization. The CJT demonstrates that the collective decisions by organizations under these types of ambiguity are still superior to individual decisions. Condition 1 is, therefore, largely satisfied.

If rational actors are willing to invest their time and money in founding a new organization, they should more or less "know what they are doing," in the sense that, while they may not always make the right decisions, they can do so more often than not. Since founding a new organization requires a large investment of many individual resources, and since individual resources are always limited, rational actors will not attempt to found an organization when they are utterly incapable of making the right decisions (Condition 2). ${ }^{10}$ Note that some of the individual members may have $p<\frac{1}{2}+1 / 2 n$, as long as there are other more competent members to bring up the mean to at least $1 / 2+1 / 2 n$. If the individuals in a partnership are particularly deficient in some areas of expertise (finance, PR,

10 Note, however, that this does not mean that organizations founded by competent individuals (in this sense) will necessarily succeed. While the mean competence of founders probably has a positive effect on the likelihood of organizational survival, there are many factors beyond the founders' control that affect the fate of their newly founded organization (such as the levels of competition and legitimation in the environment). Organizational survival belongs at the macro level, not in the microprocess of decision making on organizational founding that I am using as an example here. 
applicable laws, etc.), they will probably seek out either other partners who are competent in these areas or pertinent information to increase their own competence, so that, collectively, their mean competence will be reasonably high.

While there may be some interpersonal influence among the members to make individual decisions positively correlated, the CJT will still hold and the collective decisions will be superior to the mean individual's, as long as the opinion leaders are not highly competent (Condition 3). If founding members of an organization fight among themselves, there may even be a negative correlation among their decisions. Coalitions, factions, disagreements, differences of opinions, different judgment styles, and other sources of negative correlations are all conducive to the superiority of collective decisions.

While some find that competent members are more likely to emerge as the opinion leaders in small groups (Hollander, 1964; De Souza and Klein, 1995), others find that such factors clearly orthogonal to competence as visibility (how well an individual can see and be seen by others, mostly as a function of seating arrangement at the discussion table) and physical size (height and weight) are also highly conducive to the opinion leader status (Crosbie, 1979; Baker, 1988). Given this empirical evidence, it is reasonable to suppose that opinion leaders are not generally more competent than other group members. Therefore, the CJT holds, and the use of human subjects in the role of organizations is justified.

Negative correlations of opinions created by coalitions and conflict within the group make it easier for the CJT to hold. Franz and Jin (1995) note that conflict is ubiquitous in collaborative work groups, making individual decisions negatively correlated. Consistent with Ladha $(1992,1995)$ and my results in Table 1, Jehn (1995) finds that task conflict is sometimes beneficial to groups performing nonroutine tasks (where there is some uncertainty about the correct choices).

Finally, it is reasonable to suppose that founders in many new ventures follow democratic means of arriving at collective decisions by using a majority rule (Condition 4). Unfortunately, an extensive search of the organizational literature has revealed no empirical study of how decisions are made among members of potential new organizations during the founding process. However, Gastil (1993, Table 2) finds that an overwhelming majority of groups in which undergraduate students are routinely involved (ranging from women's soccer teams to religious associations to Army reserve units to task groups in $3 \mathrm{M}$ and Motorola; $n=65$ ) employs the one-person, one-vote democratic means of making group decisions.

Figure 1 presents the density dependence theory in multiple levels, in a

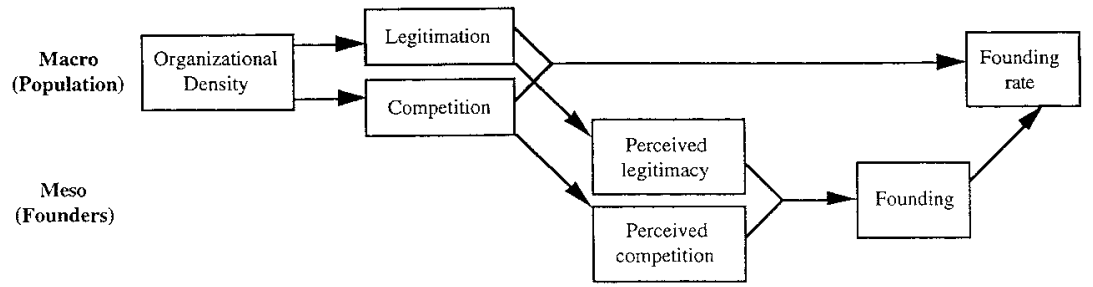

FIG. 1. Density dependence theory in multiple levels. 
modified Coleman boat. ${ }^{11}$ All past empirical tests of the density dependence theory were at the macro level, testing the causal effect of organizational density on the founding rate in the population. A laboratory experiment with human subjects can test the theory's "microfoundations": a combined causal effect of perceived legitimacy and perceived competition on founding. The microfoundations of the density dependence theory of organizational founding will be at the meso level, where corporate actors (in this case, potential founders) are the theoretical and empirical unit of analysis (Hannan, 1992, p. 128). The microfoundation of the density dependence theory at the meso level, however, would still be a macro organizational theory, because the actor in such a theory is still the organization, not the individual.

\section{Experimental Design}

Since the corporate actor "potential founder" reasonably meets all four sufficient conditions enumerated above, a laboratory experiment can test the microfoundation of the density dependence theory of organizational foundings. The experiment will test the interaction effect of perceived legitimacy and perceived competition on organizational foundings. I will present one potential design for such an experiment in this section, but it is by no means the only design.

Organizational founders in natural settings pursue a variety of goals (making a profit, influencing politics, serving the religious community, etc.) and aim to achieve these goals by founding an organization. HC's theory, however, is a general theory of organizational foundings and is applicable to organizations of all types (as is evident from the fact that the theory has been tested and supported with data on a variety of organizations). The goals of the organizations are irrelevant for the theory, and the theory's scope condition encompasses all organizational goals.

The experimenter will therefore be able to use any goal for the organizational for the purpose of experimental testing (because any organizational goal falls under the theory's scope condition). The standard motivator for human subjects in laboratory experiments is the desire to earn money. The experimenter can guarantee that the subjects are motivated to earn as much money as possible by recruiting only those who explicitly state this desire as the reason for their participation. The goal of the "organization" in this experiment (represented by

11 I interpret legitimation or taken-for-grantedness in the density dependence theory to be operative at the level of individual actors. "A(n) [organizational] form acquires legitimation in this [taken-forgrantedness] sense when there is little question in the minds of actors that it serves as the natural way to effect some kind of collective action" (HC, 1992, p. 34; emphasis added). However, this taken-for-grantedness must be widely shared within a population: "The persons, corporate actors, and social networks comprising the sets of actors in each market presumably act on shared images of reality, including implicit definition of appropriate organizational forms" (HC, 1992, p. 36). I therefore put "legitimation" at the macro (population) level in Fig. 1 and "perceived legitimacy" at the level of meso actors. 
the human subject) will therefore be making as much money as possible (similar to the goals of capitalist firms).

Upon arrival at the laboratory, the human subjects will be separated in individual rooms, with no contact with other subjects before, during, or after the experiment. They will play some preliminary game or task for which all subjects will earn an equal amount of money (say $\$ 10$ ). This procedure is necessary to have the subjects believe that they have earned the money, rather than simply being given it by the experimenter for no reason. (This is analogous to the potential founders having earned the capital prior to their decision to found an organization and invest the money in it.)

At the end of this preliminary game, all subjects will be given an opportunity to increase their earnings by playing some gamble or lottery. The subject must pay $\$ 5$ (out of their $\$ 10$ earnings) to play this gamble, and, if they win, they will earn $\$ 50$. However, the subjects will not know the odds of winning, in order to prevent their expected value calculations. In natural settings, potential founders might know the costs of failure and the benefits of success, but they seldom, if ever, know the odds of success of their organization, should they choose to found it. Their decision to play the gamble will be the experimental analog of the potential founder's decision to found an organization. Any transaction cost of founding (which individuals incur only if they decide to found an organization) can be part of the $\$ 5$ cost of the gamble.

Perceived legitimacy will be manipulated as the extent to which this form of pursuing their goals (earning money) is "taken-for-granted" for the subjects in similar situations. In the "high perceived legitimacy" condition, the subjects will be given the following instructions.

The past research in this area has shown that experimental subjects, such as yourself, who are given a similar opportunity to increase their earnings at the end of the experiment, usually take the opportunity to do so. Our past experience with conducting similar experiments also leads us to believe that subjects in your situation will probably take this opportunity.

The subjects in the "low perceived legitimacy" condition will be told that the past research has shown that subjects in similar situations usually do not take such an opportunity to increase their earnings, and therefore the experimenters do not expect their subjects to do so.

Perceived competition will be manipulated as the extent to which the subject must share the available resources with others in the local population. In the "high perceived competition" condition, the subjects will be given the following instructions.

There are five other subjects in this experimental session, and they will also be making their decisions whether or not to enter this gamble to increase their earnings. Regardless of how many of you choose to enter this gamble, there will only be one drawing, only one chance to 
win or lose, for all of you. If you win, you will have to share your winning (\$50) equally with any or all of the others who have also chosen to enter the gamble.

The subjects in the "low perceived competition" condition will be told that there is one other subject in the experimental session, and they will have to share the winning (\$50) with her should she also elect to enter the gamble. Sharing the winning of the gamble with few or many others is analogous to competition for "market share." For any given level of market demand for a good or a service, the greater the competition (the larger the number of other organizations that produce the same good or service), the lower the returns to any given organization.

Note that, consistent with HC's (1992) theory, both legitimacy and competition are implicitly operationalized as a function of population density (see Fig. 1). Legitimacy (and perceived legitimacy) increases with the number of other subjects who have also taken the gamble (i.e., found a particular form of organization) in the past, in previous experiments. Competition (and perceived competition) increases with the number of other subjects who must potentially share the available resources in the local population (i.e., the number of competitors in the local market niche).

The theory predicts that perceived legitimacy has a positive effect, and perceived competition has a negative effect, on organizational foundings. The two key variables will be manipulated between subjects in this experiment. The experimental hypothesis would, therefore, be that the two treatments will have an interaction effect, and more subjects will choose to enter the gamble in the "high perceived legitimacy, low perceived competition" cell in the $2 \times 2$ table than those in any other cell.

\section{CONCLUSION}

HC's (1992) density dependence theory of organizational foundings is just one example of macro organizational theory with corporate actors that satisfies the four sufficient conditions for experimental testing. I contend that many other, though certainly not all, general and abstract macro organizational theories are excellent candidates for testing in laboratory experiments. For instance, human subjects can play the role of corporations, and an experiment can examine how network ties and economic sectors constrain corporations' ability to pursue higher profits (Burt, 1983). Another experiment can test the tenets of resource dependence theory (Pfeffer and Salancik, 1978) and demonstrate how organizations respond to external constraints imposed by their environments. Human subjects can also play the role of subunits within an organization, such as academic departments within a university (Pfeffer and Salancik, 1974; Salancik and Pfeffer, 1974; Pfeffer and Moore, 1980), divisions and sections within a firm, or coalitions and cliques within an office, and a laboratory experiment can examine their behavior with respect to each other.

Whatever corporate actor the human subjects represent, laboratory experiments will allow more precise manipulations of key variables and permit the researcher 
to observe the behavior of the "organizations" (or their subunits) more closely. Such experimental testing is not only justified, but also preferred to nonexperimental testing because the experiments uniquely combine rigor and statistical conservativeness.

\section{REFERENCES}

Abell, P. (1989). “Games in networks: A sociological theory of voluntary associations,” Rationality and Society 1, 259-282.

Ainslie, G. (1992). Picoeconomics: The Strategic Interaction of Successive Motivational States within the Person, Cambridge Univ. Press, Cambridge.

Arminger, G., and Bohrnstedt, G. W. (1987). "Making it count even more: A review and critique of Stanley Lieberson's Making It Count: The Improvement of Social Theory and Research," in Sociological Methodology, Vol. 17 (C. C. Clogg, Ed.), pp. 363-372, American Sociological Association, Washington, DC.

Aronson, E., Brewer, M., and Carlsmith, J. M. (1985). "Experimentation in social psychology," in Handbook of Social Psychology, 3rd edition, Vol. 1 (G. Lindzey and E. Aronson, Ed.), pp. 441-486, Random House, New York.

Arrow, K. J. (1963). Social Choice and Individual Values, 2nd edition, Yale Univ. Press, New Haven. Baker, P. M. (1988). "Participation in small groups: Social, physical, and situational predictors," Small Group Research 19, 3-18.

Berger, J., Eyre, D. P., and Zelditch, M., Jr. (1989). "Theoretical structures and the micro/macro problem," in Sociological Theories in Progress, Vol. 3 (J. Berger, M. Zelditch, Jr., and B. Anderson, Eds.), pp. 11-32, Houghton Mifflin, Boston.

Berk, R. A. (1988). "Causal inference for sociological data," in Handbook of Sociology (N. J. Smelser, Ed.), pp. 155-172, Sage, Beverly Hills.

Black, D. (1958). The Theory of Committees and Elections, Cambridge Univ. Press, Cambridge.

Boland, P. J. (1989). "Majority systems and the Condorcet jury theorem," The Statistician 38, 181-189.

Burt, R. S. (1983). Corporate Profits and Cooptation: Networks of Market Constraints and Directorate Ties in the American Economy, Academic Press, New York.

Carroll, G. R., and Hannan, M. T. (1989a). "Density dependence in the evolution of populations of newspaper organizations," American Sociological Review 54, 524-541.

Carroll, G. R., and Hannan, M. T. (1989b). "On using institutional theory in studying organizational populations," American Sociological Review 54, 545-548.

Carroll, G. R., and Swaminathan, A. (1991). "Density dependent organizational evolution in the American brewing industry from 1633 to 1988," Acta Sociologica 34, 155-175.

Cohen, B. P. (1989). Developing Sociological Knowledge: Theory and Method, 2nd Edition, Nelson-Hall, Chicago.

Condorcet, M. de. (1785). Essai sur l'application de l'analyse à la probabilité des décisions rendues à la pluralité des vox, Imprimerie Royale, Paris, France.

Condorcet, M. de. (1976). Condorcet: Selected Writings (K. M. Baker, Ed. and intro.), Bobbs-Merrill, Indianapolis.

Coleman, J. S. (1990). Foundations of Social Theory, Harvard Univ. Press, Cambridge.

Cook, T. D., and Campbell, D. T. (1979). Quasi-Experimentation: Design and Analysis Issues for Field Settings, Houghton Mifflin, Boston.

Costner, H. L., and Blalock, H. M. (1972). "Scientific fundamentalism and scientific utility: Reply to Gibbs," Social Science Quarterly 52, 827-824.

Costner, H. L., and Leik, R. K. (1964). "Deductions from 'axiomatic theory',” American Sociological Review 29, 819-835.

Crosbie, P. V. (1979). “The effects of sex and size on status ranking," Social Psychology Quarterly 42, 340-354. 
De Souza, G., and Klein, H. J. (1995). “Emergent leadership in the group goal-setting process,” Small Group Research 26, 475-496.

Elster, J. (1989). The Cement of Society: A Study of Social Order, Cambridge Univ. Press, Cambridge. Emerson, R. M. (1962). "Power-dependence relations," American Sociological Review 27, 31-41.

Estlund, D. M. (1994). "Opinion leaders, independence, and Condorcet jury theorem," Theory and Decision 36, 131-162.

Feld, S. L., and Grofman, B. (1990). "Collectivities as actors: Consistency of collective choices," Rationality and Society 2, 429-448.

Franz, C. R., and Jin, K. G. (1995). "The structure of group conflict in a collaborative work group during information systems development," Journal of Applied Communication Research 23, $108-127$.

Friedman, D. (1986). "The principal-agent problem in labor-management negotiations," in Advances in Group Processes, Vol. 3, (E. J. Lawler, Ed.), pp. 89-106, JAI Press, Greenwich.

Garman, M. B., and Kamien, M. I. (1968). "The paradox of voting: Probability calculations," Behavioral Science 13, 306-323.

Gastil, J. (1993). "Identifying obstacles to small group democracy," Small Group Research 24, 5-27.

Gehrlein, W. V., and Fishburn, P. C. (1976). "The probability of the paradox of voting: A computable solution," Journal of Economic Theory 13, 14-25.

Grofman, B., and Feld, S. L. (1988). "Rousseau's general will: A Condorcetian perspective," American Political Science Review 82, 567-576.

Hannan, M. T. (1991). Aggregation and Disaggregation in the Social Sciences (Rev. ed.), Lexington Books, Lexington.

Hannan, M. T. (1992). "Rationality and robustness in multilevel systems," in Rational Choice Theory: Advocacy and Critique, (J. S. Coleman and T. J. Fararo, Eds.), pp. 120-136, Sage Publications, Beverly Hills.

Hannan, M. T., and Carroll, G. R. (1992). Dynamics of Organizational Populations: Density, Legitimation, and Competition, Oxford Univ. Press, New York.

Hannan, M. T., and Freeman, J. (1987). "The ecology of organizational founding: American labor unions, 1836-1985," American Journal of Sociology 92, 910-943.

Hannan, M. T., and Freeman, J. (1988). "The ecology of organizational mortality: American labor unions, 1836-1985," American Journal of Sociology 94, 25-52.

Hannan, M. T., and Freeman, J. (1989). Organizational Ecology, Harvard Univ. Press, Cambridge.

Hannan, M. T., Ranger-Moore, J., and Banaszak-Holl, J. (1990). "Competition and the evolution of organizational size distributions," in Organizational Evolution: New Directions (J. V. Singh, Ed.), pp. 246-268, Sage Publications, Newbury.

Holland, P. W. (1986). "Statistics and causal inference," Journal of the American Statistical Association 81, 945-960.

Hollander, E. P. (1964). Leaders, Groups and Influence, Oxford Univ. Press, New York.

Jehn, K. A. (1995). "A multimethod examination of the benefits and detriments of intragroup conflict," Administrative Science Quarterly 40, 256-282.

Jensen, M. C., and Meckling, W. H. (1976). "Theory of the firm: Managerial behavior, agency costs and ownership structure," Journal of Financial Economics 3, 305-360.

Kanazawa, S. (1998). "A brief note on a further refinement of the Condorcet jury theorem for heterogeneous groups," Mathematical Social Sciences 35, 69-73.

Ladha, K. K. (1992). "The Condorcet jury theorem, free speech, and correlated votes," American Journal of Political Science 36, 617-634.

Ladha, K. K. (1995). "Information pooling through majority-rule voting: Condorcet's jury theorem with correlated votes," Journal of Economic Behavior and Organization 26, 353-372.

Lawler, E. J., Ridgeway, C., and Markovsky, B. (1993). "Structural social psychology and the micro-macro problem," Sociological Theory 11, 268-290.

Lomi, A. (1995). “The population ecology of organizational founding: Location dependence and unobserved heterogeneity," Administrative Science Quarterly 40, 111-144. 
March, J. G., and Olsen, J. P. (Eds.) (1976). Ambiguity and Choice in Organizations, Universitetsforlaget, Bergen, Norway.

Martin, M. W., and Sell, J. (1979). "The role of the experiment in the social sciences," Sociological Quarterly 20, 581-590.

McClelland, D. C. (1961). The Achieving Society, Nostrand, Princeton.

McLean, I., and Hewitt, F. (1994). Condorcet: Foundations of Social Choice and Political Theory, Edward Elgar, Brookfield.

Miller, N. R. (1986). "Information, electorates, and democracy: Some extensions and interpretations of the Condorcet jury theorem," in Information Pooling and Group Decision Making: Proceedings of the Second University of California, Irvine, Conference on Political Economy (B. Grofman and G. Owen, Eds.), pp. 173-192, JAI Press, Greenwich.

Niemi, R. G., and Weisberg, H. F. (1968). "A mathematical solution for the probability of the paradox of voting," Behavioral Science 13, 317-323.

Péli, G., Bruggeman, J., Masuch, M., and Ó Nualláin, B. (1994). “A logical approach to formalizing organizational ecology," American Sociological Review 59, 571-593.

Petersen, T. (1993). "The economics of organization: The principal-agent relationship," Acta Sociologica 36, 277-293.

Pfeffer, J., and Moore, W. L. (1980). "Power in university budgeting: A replication and extension," Administrative Science Quarterly 25, 637-653.

Pfeffer, J., and Salancik, G. R. (1974). "Organizational decision making as a political process: The case of a university budget," Administrative Science Quarterly 19, 135-151.

Pfeffer, J., and Salancik, G. R. (1978). The External Control of Organizations: A Resource Dependence Perspective, Harper and Row, New York.

Plott, C. R. (1967). "A notion of equilibrium and its possibility under majority rule," American Economic Review 57, 787-806.

Salancik, G. R., and Pfeffer, J. (1974). "The bases and use of power in organizational decision making: The case of a university," Administrative Science Quarterly 19, 453-473.

Schelling, T. C. (1984). Choice and Consequence, Harvard Univ. Press, Cambridge.

Skog, O. J. (1993). "The voting paradox in socially integrated populations," Acta Sociologica 36, 207-222.

Walker, H. A., and Cohen, B. P. (1985). "Scope statements: Imperatives for evaluating theory," American Sociological Review 50, 288-301.

Weick, K. E. (1965). "Laboratory experimentation with organizations," in Handbook of Organizations (J. G. March, Ed.), pp. 194-260, Rand McNally, Chicago.

Zelditch, M., Jr. (1969). "Can you really study an army in the laboratory?" in A Sociological Reader on Complex Organizations (A. Etzioni, Ed.), pp. 528-539, Holt, Rinehart and Winston, New York.

Zelditch, M., Jr., and Hopkins, T. K. (1961). "Laboratory experiments with organizations," in Complex Organizations: A Sociological Reader (A. Etzioni, Ed.), pp. 464-478, Holt, Rinehart and Winston, New York.

Zucker, L. G. (1977). “The role of institutionalization in cultural persistence,” American Sociological Review 42, 726-743.

Zucker, L. G. (1989). “Combining institutional theory and population ecology: No legitimacy, no history?" American Sociological Review 54, 542-545. 